\title{
Letter
}

Martin J.D. Clift*, Sabine Frey, Carola Endes, Vera Hirsch, Dagmar A. Kuhn, Blair D. Johnston, Peter Wick, Alke Petri-Fink and Barbara Rothen-Rutishauser

\section{Assessing the impact of the physical properties of industrially produced carbon nanotubes on their interaction with human primary macrophages in vitro}

\begin{abstract}
Currently it is not fully understood how carbon nanotubes (CNTs) may affect human health. Despite this, CNTs are produced at a tonne mass scale yearly. Due to their large production and intended use within a variety of applications it is imperative that a clear understanding of the hazard potential of CNTs is gained. The aim of this study therefore was to assess the impact of five different industrially produced CNTs which varied in their physical properties on the viability of human monocyte derived macrophages (MDM), and subsequently, at sub-lethal concentrations $(0.005-0.02 \mathrm{mg} / \mathrm{mL})$, their ability to cause oxidative stress and a pro-inflammatory response in these important immune cells over a 24-h period. None of the CNTs caused significant cytotoxicity up to $0.02 \mathrm{mg} / \mathrm{mL}$ after $24 \mathrm{~h}$. Only the long multi-walled CNTs (MWNCTs) caused a significant, dose-dependent $(0.005-0.02 \mathrm{mg} / \mathrm{mL})$ reactive oxygen species production, whilst bundled MWCNTs showed a significant tumor necrosis factor alpha release after $24 \mathrm{~h}$ exposure at $0.02 \mathrm{mg} / \mathrm{mL}$. No effects were observed for either tangled MWCNTs or short MWCNTs. It can be concluded from the findings of the present study that the industrially produced CNTs studied can cause hazardous effects in vitro that may be associated with their physical properties.
\end{abstract}

Keywords: carbon nanotubes (CNTs); industrial CNTs; monocyte derived macrophages (MDM); nanofiber-cell interaction; oxidative stress; pro-inflammatory response.

*Corresponding author: Martin J.D. Clift, BioNanomaterials, Adolphe Merkle Institute, University of Fribourg, Rte de L'Ancienne Papeterie, 1723, Marly 1, Fribourg, Switzerland, Phone: +41 (0)26 30095 17; Fax:+41(0)2630096 24, E-mail: martin.clift@unifr.ch Sabine Frey, Carola Endes, Vera Hirsch, Dagmar A. Kuhn and Blair D. Johnston: BioNanomaterials, Adolphe Merkle Institute, University of Fribourg, Rte de l'Ancienne Papeterie, 1723, Marly 1, Fribourg, Switzerland
Peter Wick: Empa, Swiss Federal Laboratories for Material Science and Technology, Materials-Biology Interactions Laboratory, Lerchenfeldstrasse 5, CH-9014, St. Gallen, Switzerland Alke Petri-Fink: BioNanomaterials, Adolphe Merkle Institute, University of Fribourg, Rte de l'Ancienne Papeterie, 1723, Marly 1, Fribourg, Switzerland; and Department of Chemistry, University of Fribourg, Chemin du Museé 9, 1700 Fribourg, Switzerland Barbara Rothen-Rutishauser: BioNanomaterials, Adolphe Merkle Institute, University of Fribourg, Rte de l'Ancienne Papeterie, 1723, Marly 1, Fribourg, Switzerland; and Respiratory Medicine, Bern University Hospital, Inselspital, Freiburgstrasse, CH-3010 Bern, Switzerland

\section{Introduction}

Carbon nanotubes (CNTs) are currently produced on a mass scale basis (11-1,000 tonnes per year [1]) and are potentially advantageous for numerous consumer, industrial and medical applications due to their unique physical properties [2, 3]. Human exposure to CNTs during their production is considered inevitable, as it is during their use within any potential application [4]. Although alternative routes exist, the main exposure route for CNTs to enter the human body is considered to be the lung, via inhalation [5-7]. If CNTs enter into the human lung, it is accepted that they may activate the innate immune response and interact with important immune cells (i.e., macrophages) at the epithelial airway barrier [8]. This interaction can subsequently trigger a variety of intracellular signaling cascades leading to potentially adverse effects detrimental to human health $[9,10]$.

Over the past few years, in an aid to try and understand the potential risk posed by these advantageous materials towards human health, a growing literature base has produced a vast array of risk assessment (hazard $\times$ exposure) [11] studies of the CNT-cell interaction and the subsequent biochemical effects caused [12, 13]. 
Despite the many studies performed, a clear understanding as to the specific exposure levels of CNTs towards humans is not evident. In addition to the landmark study by Maynard and colleagues in 2004 which estimated workers within a CNT manufacturing plant to be exposed to $53 \mu \mathrm{g} / \mathrm{m}^{3}$ of aerosolized CNTs [5], only a recent NIOSH report has managed to suggest a human CNT exposure limit of $1 \mu \mathrm{g} / \mathrm{m}^{3}$ (previously considered as $7 \mu \mathrm{g} / \mathrm{m}^{3}$ [14]). These limits however, were founded upon on a number of high-profile studies using, debatably, overload doses in vivo [15-22]. It is imperative therefore that these findings are confirmed within a realistic occupational setting (i.e., CNT manufacturing plant).

In terms of hazard assessment, a plethora of studies, from both an in vitro and in vivo perspective have investigated how a variety of different CNT types (predominantly single-walled and multi-walled CNTs (MWCNTs) may elicit an adverse biological effect [13]. Due to their increased strength and durability owing to the multiple graphene layers, and thus high applicability towards industrial exploitation within a range of applications, the main focus of this research has been towards MWCNTs [3]). The most important finding conveyed from such studies has been that, based on the Stanton theory of fibers [23], if CNTs are both extremely long and stiff, as well as being biopersistent, then they are able to elicit 'asbestos-like' effects; i.e., the formation of inflammatory granulomas on the peritoneal cavity of female $\mathrm{C} 57 \mathrm{Bl}$ mice after 7 days exposure at a final dose of $50 \mu \mathrm{g}$ per animal [24]. From these findings, it is evident that the production and use within consumer applications of CNTs with these specific physical properties should not be considered further due to their implications on human health. Many other CNTs are being produced however, with a variety of alternative physical properties (e.g., bundled, tangled and short CNTs). Equivocal results regarding their (potential) hazard however, have been reported. In 2010, Johnston and colleagues published an extensive overview of the literature associated with CNT-cell interactions/effects, highlighting that CNTs can cause a range of biological effects [e.g., cytotoxicity, oxidative stress and (pro-)inflammatory reactions] both in vitro and in vivo [13]. Yet, despite such an exhaustive review of the literature, no clear correlation between CNT physical characteristics and a specific biological response - apart from those CNTs fitting the fiber paradigm [i.e., long $(>15 \mu \mathrm{m})$, high aspect ratio $(\geq 1: 3)$ and biopersistent] [24-27] - was noted. The inability to show any clear findings in regard to the physical properties of bundled, tangled and short CNTs was attributed to discrepancies in (i) the production method (e.g., chemical vapor deposition vs. arc discharge) of CNTs [3], and thus (ii) levels of contaminant metals in the CNT sample [2830], (iii) the dose and exposure method used [31] and (iv) the biological system employed (i.e., in vitro vs. in vivo) [8]. By controlling such variables, and in an attempt to only consider the sole biological impact of CNT physical properties [32], the aim of this study was to focus upon the cellular response of five physically different and currently industrially produced CNTs (Table 1). To achieve this, human monocyte derived macrophages (MDM) were employed as a model, immune cell in vitro system. MDM were exposed via suspension culture to each different CNT type [all produced via the chemical vapor deposition (CVD) method] and subsequently assessed for their

Table 1 Overview of the key physico-chemical characteristics of the single-walled (bundled) CNTs (SWCNTs), multi-walled (bundled) CNTs (MWNCTs), long MWCNTs (NTL), tangled MWCNTs (NTT) and short MWCNTs (NTS) used in the present study.

\begin{tabular}{|c|c|c|c|c|c|c|}
\hline CNT & Morphology & Supplier & Length, $\mu \mathrm{m}$ & Width, nm & Endotoxin & Contaminant metals \\
\hline SWCNT & Bundled & $\begin{array}{l}\text { Yangtze } \\
\text { Nanotechnology } \\
\text { (CHINA) }\end{array}$ & $0.5-3^{a}$ & $20^{\mathrm{a}}$ & ND & $(\% w t): \mathrm{Ni}(5.5), \mathrm{Y}(0.7)^{\mathrm{b}}$ \\
\hline MWCNT & Bundled & $\begin{array}{l}\text { Cheap Tubes } \\
\text { (Bayer) (DE) }\end{array}$ & $1-10^{\mathrm{b}}$ & $5-30^{b}$ & $\mathrm{ND}^{\mathrm{e}}$ & $\begin{array}{l}\text { (\% wt): Fe (0.05), Mg (0.01), Ni (0.12), } \\
\text { Co }(<0.001)^{b}\end{array}$ \\
\hline MWCNT & $\begin{array}{l}\text { Long, Straight, Stiff } \\
\text { (NTL) }\end{array}$ & Mitsui \& Co. (JAPAN) & $56(\max )^{c}$ & $165(\max )^{c}$ & $\mathrm{ND}^{c}$ & $\begin{array}{l}(\mu \mathrm{g} / \mathrm{g}): \mathrm{Fe}(37.3), \mathrm{Cu}(1.2), \mathrm{V}(\mathrm{ND}) \\
\mathrm{Ni}(6.2), \mathrm{Zn}(\mathrm{ND}), \mathrm{Co}(3.4)^{\mathrm{c}}\end{array}$ \\
\hline MWCNT & Tangled (NTT) & NanoLab (USA) & $5-20^{c}$ & $10(\max )^{c}$ & $N^{c}$ & $\begin{array}{l}(\mu \mathrm{g} / \mathrm{g}): \mathrm{Fe}(13.4), \mathrm{Cu}(1), \mathrm{V}(\mathrm{ND}), \mathrm{Ni}(5) \\
\mathrm{Zn}(7.5), \mathrm{Co}(\mathrm{ND}) \mathrm{c}\end{array}$ \\
\hline MWCNT & $\begin{array}{l}\text { Short and straight } \\
\text { (NTS) }\end{array}$ & $\begin{array}{l}\text { Nanostructured } \\
\text { and Amorphous } \\
\text { Materials Inc. (USA) }\end{array}$ & $0.5-2^{d}$ & $5-10^{d}$ & ND & $\begin{array}{l}(\mu \mathrm{g} / \mathrm{g}): \mathrm{Cd}(<0.1), \mathrm{Co}(<0.1), \mathrm{Cr}(<0.1), \\
\mathrm{Cu}(<0.1), \mathrm{Fe}(24.2), \mathrm{Mn}(50.3), \mathrm{Ni}(21.6), \\
\mathrm{Ti}(0.4), \mathrm{V}(<0.1), \mathrm{Zn}(5.3)^{d}\end{array}$ \\
\hline
\end{tabular}

All data presented is compiled from previous research studies (aWick et al. [33]; 'Thurnherr et al. [34]; 'Poland et al. [24]; ' ${ }^{\mathrm{d}}$ Murphy et al. [26] and ${ }^{\mathrm{C}} \mathrm{Clift}$ et al. [10]) that investigated the length, width, supplier, morphology, endotoxin levels and contaminant metals for each different CNT sample. ND refers to not detectable via the LAL endotoxin assay. 
influence upon MDM viability (cytotoxicity) and ability to produce reactive oxygen species (ROS), as well as to stimulate pro-inflammatory cytokine release. It was hypothesized that CNT morphology alone would drive any adverse effects observed.

\section{Results}

\section{Cytotoxicity}

No significant cytotoxicity ( $\mathrm{p}>0.05$ ), as measured by the release of the cytosolic enzyme lactate dehydrogenase (LDH), was observed for any of the five different CNT samples (as described per their key physico-chemical characteristics in Table 1) after 24-h suspension exposure up to a nanofiber concentration of $0.02 \mathrm{mg} / \mathrm{mL}$ (Figure 1A). Furthermore, no significant LDH release was observed at the concentration of $160 \mathrm{ppm}$ or $0.04 \mathrm{mg} / \mathrm{mL}$ for the dispersants Pluronic F127 and Tween 80, respectively, over the $24 \mathrm{~h}$ exposure period. No significant cytotoxic ( $p>0.05$ ) effect was noted for the $5 \%$ bovine serum albumin (i.e., BSA Media) solution used to disperse the NTL, NTT and NTS MWCNTs. It is also important to note that no significant ( $p>0.05$ ) LDH adsorption [35] was observed between the LDH enzyme and the CNTs (i.e., eliciting a false positive/negative) or dispersants tested (data not shown). Additional morphological assessment of MDM via conventional light microscopy following exposure to all CNTs and dispersants also showed no qualitative signs of cytotoxicity, supporting the quantitative data shown in Figure 1A (Figure 1B).

\section{Oxidative stress}

In a cell-free environment, no significant $(\mathrm{p}>0.05)$ ROS was observed for any of the CNTs or dispersants tested when compared to the negative control (Figure 2A). In the presence of MDM, only the long MWCNTs (NTL) showed a significant $(\mathrm{p}<0.05)$, dose-dependent increase in the production of ROS following $24 \mathrm{~h}$ exposure to $0.005-0.02 \mathrm{mg} / \mathrm{mL}$ (Figure 2B). No significant ( $p>0.05$ ) levels of oxidative stress were noted in any of the other CNT or dispersants tested when compared to the negative control (Figure 2B).

\section{Pro-inflammatory response}

Only the bundled MWCNTs, dispersed in Pluronic F127 (160 ppm), at $0.02 \mathrm{mg} / \mathrm{mL}$ showed a significant pro-inflammatory response $(\mathrm{p}<0.05)$, with an increased production in the cytokine tumor necrosis factor- $\alpha$ (TNF- $\alpha$ ) observed after $24 \mathrm{~h}$ (Figure 3). No significant ( $\mathrm{p}>0.05$ ) pro-inflammatory cytokine release was found for any of the other four CNTs tested. It is also important to note that, compared to the negative control, no significant ( $\mathrm{p}>0.05$ ) (Figure 3 ) increase in the production of TNF- $\alpha$ by MDM was observed for either Pluronic F127 or Tween 80 at 160 ppm and $0.04 \mathrm{mg} / \mathrm{mL}$, respectively. The 5\% dispersant solution (i.e., BSA Media) for the NTL, NTT and NTS MWCNT samples also caused no significant pro-inflammatory response in vitro (Figure 3). It is also important to note that no significant $(\mathrm{p}>0.05)$ protein adsorption was observed between the TNF- $\alpha$ protein and the CNTs (i.e., eliciting a false positive/negative) or dispersants tested (data not shown).

\section{Discussion}

The aim of this study was to perform a controlled in vitro investigation of the biological impact of a series of industrially produced CNTs that differed in their physical properties upon a primary in vitro model immune cell [i.e., monocyte derived macrophages (MDM)].

Assessment of the ability for each CNT type to affect macrophage viability clearly showed no cytotoxic effects up to $0.02 \mathrm{mg} / \mathrm{mL}$ following suspension exposure for $24 \mathrm{~h}$. These findings were supported by conventional light microscopy that showed the MDM to maintain their morphological aspects compared to untreated primary human macrophages. Furthermore, the findings of the present study are in support of those of Murphy et al. [27], who showed the NTT, NTL and NTS samples to be noncytotoxic (as determined via LDH release) to the THP-1 macrophage cell-line at administered concentrations (suspension exposure) ranging from 0.02 to $0.05 \mu \mathrm{g} / \mathrm{cm}^{2}$. Additionally, Clift et al. [36] reported that the MWCNTs also elicited no significant LDH release within MDM up to $0.03 \mathrm{mg} / \mathrm{mL}$, as was also seen for SWCNTs [37]. Engulfment of CNTs by MDM could not be detected due to the limited resolution of conventional light microscopy, although previous research by Clift and colleagues has shown that the MWCNTs can locate within membrane-bound vesicles inside MDM after $24 \mathrm{~h}$ suspension exposure [36], whilst the SWCNTs used in the present study are internalized and present within the cytosol of MDM [37]. It is also prudent to note that Murphy et al. [27], as well as Poland et al. [24] showed frustrated phagocytosis of the NTL sample in both THP-1 and peritoneal macrophage cells, whilst the NTT and NTS samples were both observed to be internalized within vesicles by these phagocytic immune cells [27]. 
A

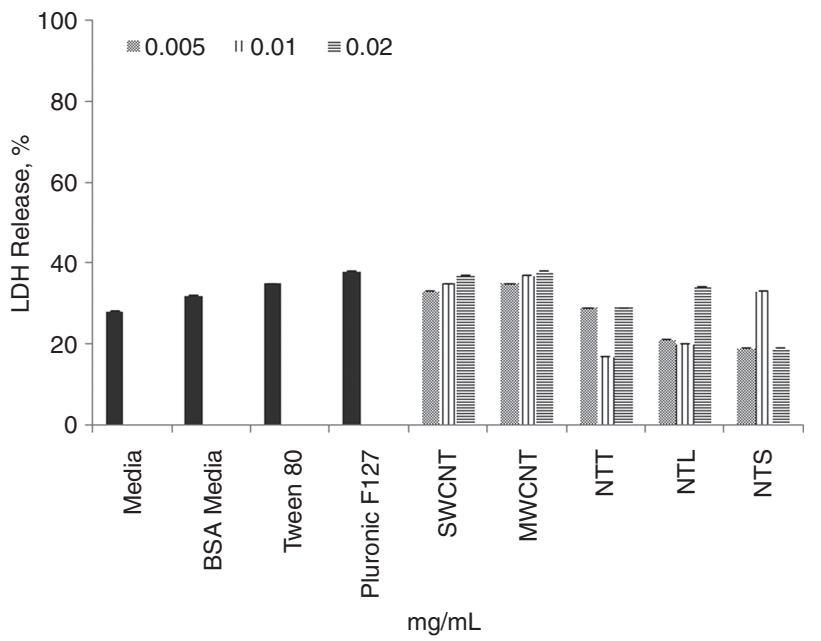

B
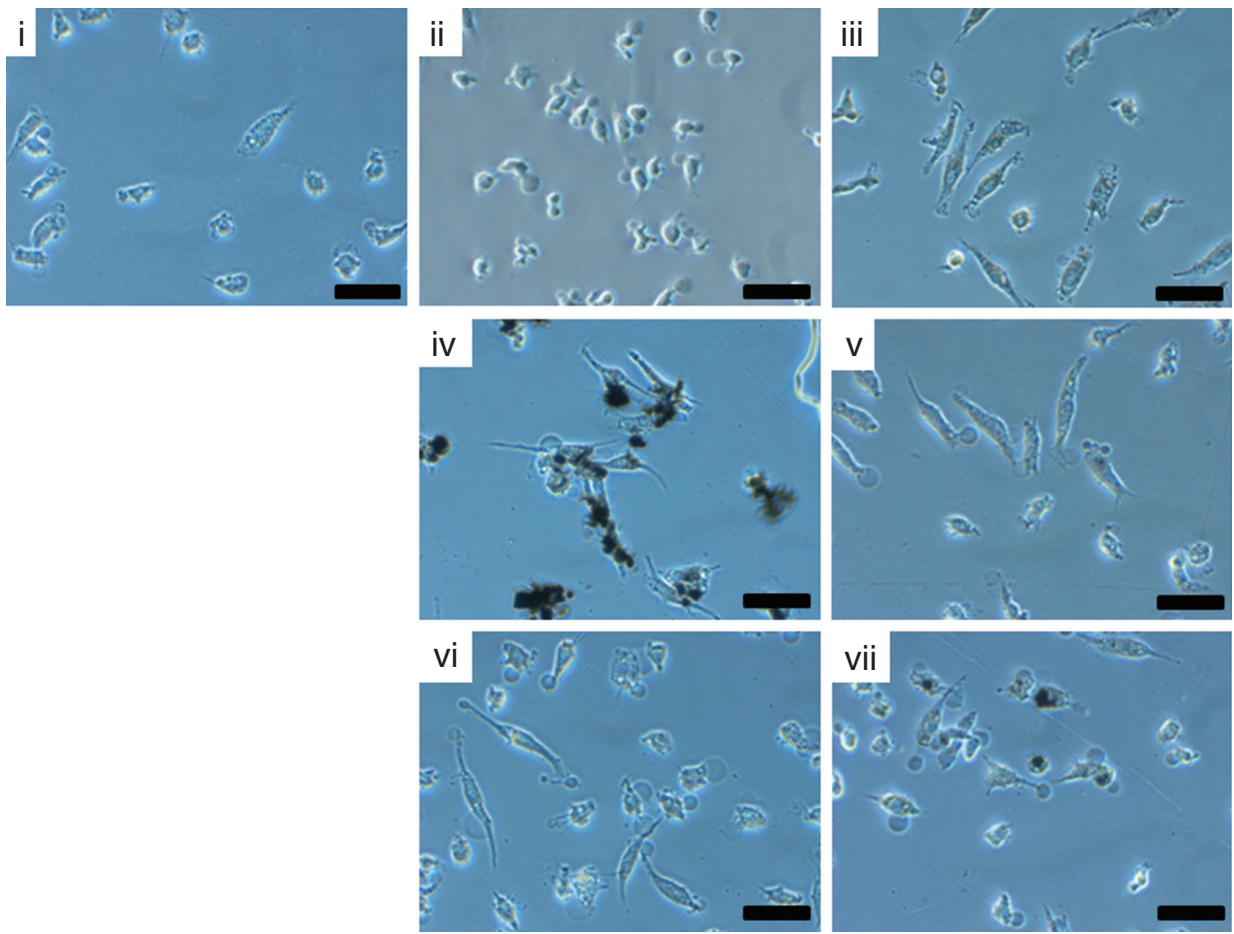

Figure 1 (A) Indicates the level of cytotoxicity, as determined by the release of the cytosolic enzyme lactate dehydrogenase (LDH), of human blood isolated monocyte derived macrophages (MDM) after exposure to single-walled CNTs (SWCNTs), multi-walled CNTs (MWNCTs), long MWCNTs (NTL), tangled MWCNTs (NTT) and short MWCNTs (NTS) for $24 \mathrm{~h}$ at $37^{\circ} \mathrm{C}, 5 \% \mathrm{CO}_{2}$ at nanofiber concentrations of $0.005,0.01$ and $0.02 \mathrm{mg} / \mathrm{mL}$. In addition, the cytotoxic effects of the CNT dispersants Pluronic F127 (160 ppm), Tween $80(0.04 \mathrm{mg} / \mathrm{mL})$ and bovine serum albumin (0.5\%) (BSA Media) are also shown. Data is normalized to the effects of the positive control $(0.2 \%$ Triton $\times 100)$. Data presented is the mean \pm standard error of the mean (SEM) $(n=3)$. (B) Shows conventional light microscopy images of the MDM exposed to the different CNT samples (i; Media only, ii; BSA Media, iii; SWCNTs, iv; MWCNTs, v; NTL, vi; NTT, vii; NTS) after $24 \mathrm{~h}$ at $37^{\circ} \mathrm{C}, 5 \% \mathrm{CO}_{2}$. In each image the scale bar (black) represents $25 \mu \mathrm{m}$.

At sub-lethal concentrations CNTs have been shown to induce the production of ROS which leads in an inflammatory response via the release of pro-inflammatory cytokines in vitro [13, 32]; thus fitting the oxidative stress paradigm - the most widely accepted paradigm concerning the potential for nano-objects to cause adverse biological effects [10]. ROS are produced from the respiratory chain in the mitochondria by generating adenosine tri-phosphate (ATP) and can induce, even at low concentrations, TNF- $\alpha$ release from the cell. This mechanism can subsequently lead to restoring the redox balance in the cell via removing the oxidative species present [38]. In the current study, only the NTL sample, in a concentration-dependent manner, was found to cause any ROS production, although 

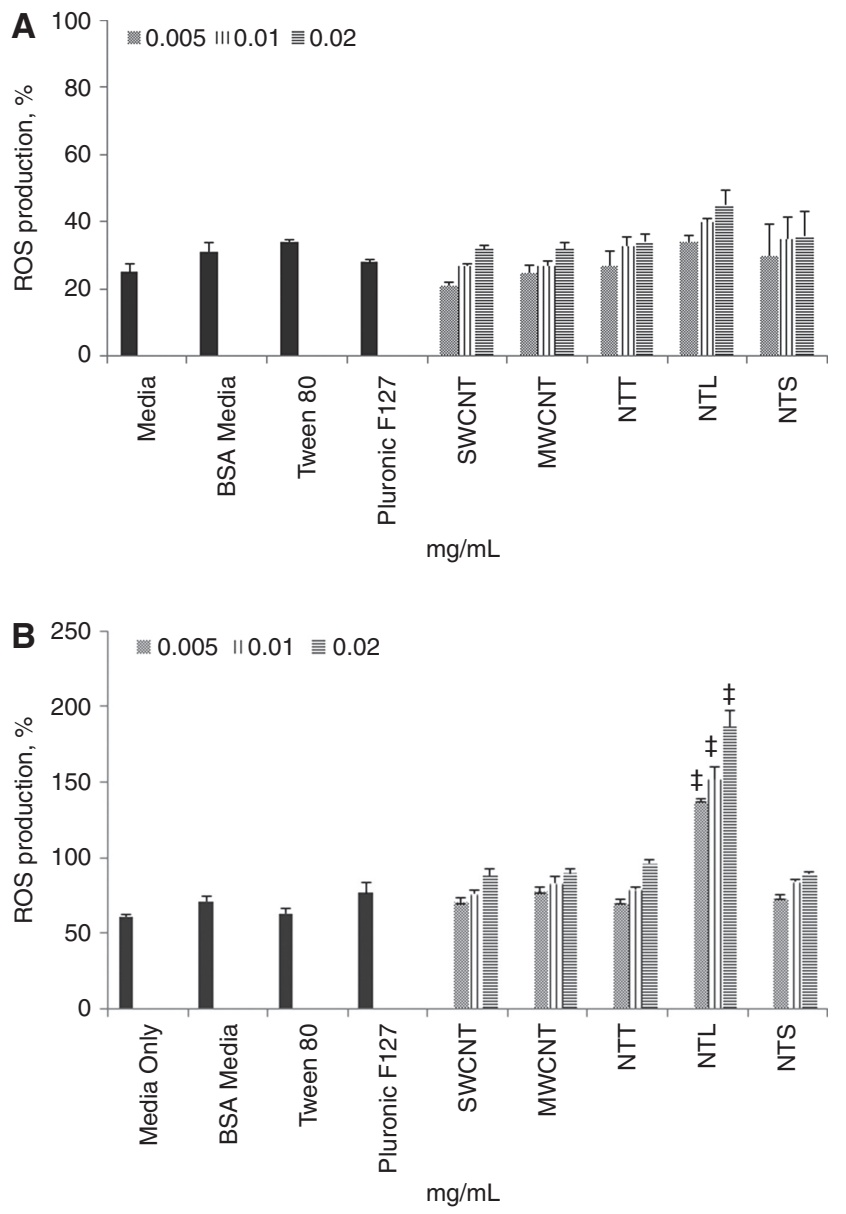

Figure 2 (A) Shows the ability for the single-walled CNTs (SWCNTs), multi-walled CNTs (MWNCTs), long MWCNTs (NTL), tangled MWCNTs (NTT) and short MWCNTs (NTS) at nanofiber concentrations of $0.005,0.01$ and $0.02 \mathrm{mg} / \mathrm{mL}$, as well as the dispersants Pluronic F127 (160 ppm), Tween $80(0.04 \mathrm{mg} / \mathrm{mL})$ and bovine serum albumin $(0.5 \%)$ (BSA Media) to produce reactive oxygen species (ROS), as determined by the DCFH-DA assay via spectrometry, in a cell-free environment. (B) Illustrates the ability for the SWCNTs, MWCNTs, NTT, NTL and NTS at $0.005,0.01$ and $0.02 \mathrm{mg} / \mathrm{mL}$, as well as the dispersants Pluronic F127 (160 ppm), Tween $80(0.04 \mathrm{mg} / \mathrm{mL})$ and bovine serum albumin ( $0.5 \%)$ to cause ROS in the presence of MDM via flow cytometry (BD LSR Fortessa). For both the cell-free and MDM experiments tert-butyl hydrogen peroxide ( $t$ bHP) (1:12,000 of $70 \%$ solution in PBS) was used. Data is normalized as a percentage against the ROS produced from the positive control ( $t$ bHP). Data presented is the mean \pm standard error of the mean (SEM) $(n=3)$. *indicates $\mathrm{p}<0.05$.

only in the presence of MDM. No significant ROS production was observed in a cell-free environment for any of the CNTs tested. The high ROS production caused by the NTL when interacting with the MDM can be attributed to the process known as 'frustrated phagocytosis' [39], and not to the increased redox potential via the high iron content, as previously confirmed by Poland et al. [24]. Frustrated phagocytosis occurs when macrophages are unable to

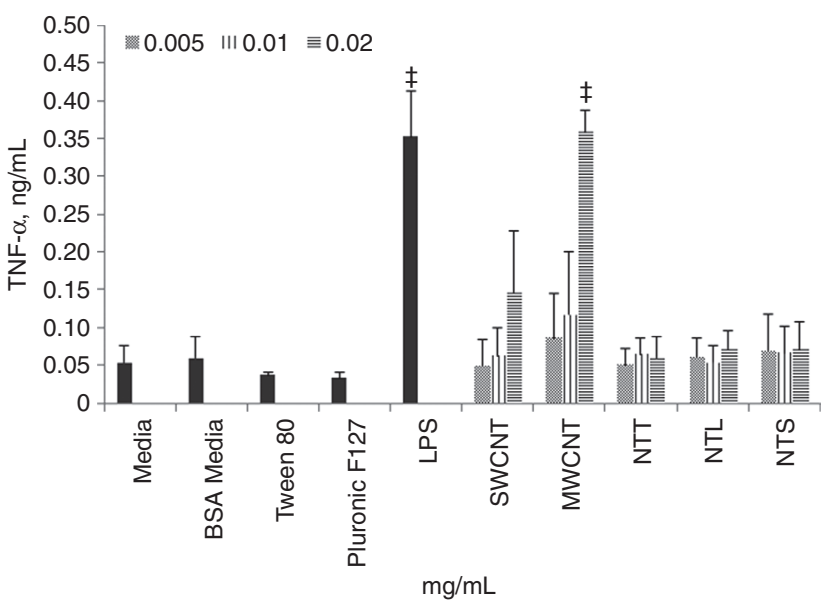

Figure 3 Shows the pro-inflammatory response for the singlewalled CNTs (SWCNTs), multi-walled CNTs (MWNCTs), long MWCNTs (NTL), tangled MWCNTs (NTT) and short MWCNTs (NTS) at nanofibre concentrations of $0.005,0.01$ and $0.02 \mathrm{mg} / \mathrm{mL}$, as well as the dispersants Pluronic F127 (160 ppm), Tween $80(0.04 \mathrm{mg} / \mathrm{mL})$ and bovine serum albumin ( $0.5 \%$ ) (BSA Media) to cause the production of the pro-inflammatory cytokine tumor necrosis factor- $\alpha$ (TNF- $\alpha$ ). Lipopolysaccharide (LPS) was used as a positive control $(0.1 \mathrm{mg} / \mathrm{mL})$. Data presented is the mean \pm standard error of the mean (SEM) $(n=3)$. *indicates $\mathrm{p}<0.05$.

successfully internalize biopersistent fibres longer than 15 $\mu \mathrm{m}$ and with a diameter $<5 \mu \mathrm{m}[39,40]$. The constant flux of the immune cell attempting to phagocytose the fibre generally causes the release of both oxidative and (pro-) inflammatory mediators that can be detrimental towards the normal homeostasis of the cell [39]. A similar effect was also reported with the same NTL MWCNTs by Brown and colleagues with the THP-1 macrophage cell-line after CNT suspension exposure of up to $62.5 \mu \mathrm{g} / \mathrm{mL}$ for $4 \mathrm{~h}$ [39]. Brown et al. [39] further showed the NTL MWCNTs to cause a significant secretion of the pro-inflammatory cytokine TNF- $\alpha$ by these immune cells, a finding that was not observed within the present study. A possible reason for the lack of TNF- $\alpha$ production observed from the MDM could be due to the different cell types used (i.e., human primary vs. a cell line), or the ELISA analysis being performed after $24 \mathrm{~h}$ post-exposure samples and not within the optimal expression/secretion of the protein [41], as it was performed in the study by Brown et al. [39].

In the present study only the MWCNTs elicited any significant TNF- $\alpha$ response from the MDM, despite the lack of any ROS production. These findings are consistent with those previously found with these MWCNTs [36] when compared to the ability for cellulose nanowhiskers to elicit a TNF- $\alpha$ response in both MDM monocultures and a sophisticated triple cell co-culture model of the epithelial airway barrier. Interestingly however, the SWCNTs showed no significant pro-inflammatory characteristics to the MDM 
after $24 \mathrm{~h}$ exposure up to $0.02 \mathrm{mg} / \mathrm{mL}$. The fact that these findings are not significant is in contrast to a recent study [37], although, the biological effects shown in both cases are the same. In the present study the lack of any statistical significance can be attributed to the high variance between repetitions, especially at the highest concentration tested. It is important to note though, that there is a clear dosedependent effect shown with the SWCNTs and that whilst this is not considered statistically significant, that this biological response can be considered influential upon cellular homeostasis when compared to the values shown with the negative control (MDM exposed to cell culture media only). In regards to the NTT and NTS MWCNTs results, the observation that neither sample showed a significant increase in either ROS or TNF- $\alpha$ production support those reported by Murphy et al. [27], in which it was found that after exposure of NTT and NTS to THP-1 cells for $24 \mathrm{~h}$ caused no significant oxidative stress or pro-inflammatory reaction after suspension exposure up to $0.05 \mu \mathrm{g} / \mathrm{cm}^{2}$ over a 24-h period [27]. It is worth noting that the lack of ROS formation, and potentially the subsequent (pro-)inflammatory response of immune cells to either the NTT or the NTS could be masked by the formation of surface groups following the extended sonication period $(4 \mathrm{~h})$. Whilst this is not the case with the NTL sample (due to the increased ROS formation shown), the intensity and duration of the sonication period, which has been shown to be optimal in suspending these CNT samples [24], could cause structural surface defects that in turn do not elucidate to true hazard potential of these CNTs. Structural defects to the surface of CNTs remains an important issue [28, 29], as previously shown by Kagan et al. [42], and requires further, in-depth investigation to understand how they may contribute to the potential adverse health effects of CNTs.

Concerning the pro-inflammatory response shown with the MWCNTs, the finding that CNTs may cause an inflammatory response, but no oxidative stress within cells compliments the findings of Shvedova et al. [18]. Shvedova and colleagues reported an initial high, dosedependent release of TNF- $\alpha$ after $24 \mathrm{~h}$ following inhalation exposure ( 4 consecutive days $5 \mathrm{~h} /$ day) or single pharyngeal aspiration of SWCNTs into mice, yet no depletion of the intracellular thiol glutathione (GSH), a key marker used to assess the oxidative potential of nanomaterials was noted. It was however, observed by Shvedova et al. [18] that GSH levels lowered after 7 and 28 days post-exposure, suggesting that deleterious effects in vivo are delayed compared to those recorded from in vitro studies; a phenomenon aptly shown by Rothen-Rutishauser et al. [43] who compared the oxidative and (pro-)inflammatory effects of MWCNTs in vitro and in vivo. The in vivo study by Shvedova and colleagues however used SWCNTs, which have been shown to cause a limited (pro-)inflammatory response when compared to that induced by MWCNTs in vitro and in vivo [13]. In a recent study Bussy et al. [44] exposed MWCNT (MWCNT treated with long lasting (7 weeks) ultrasonication in water (S-MWCNT) and MWCNT untreated (L-MWCNT)) to the murine macrophage cell-line (RAW 264.7) for 6 and $24 \mathrm{~h}$. It was found that after $6 \mathrm{~h}$ an increased pro-inflammatory response was evident. Over time however, and concomitant with an increasing expression (measured at the gene level) of superoxide dismutase-2 (SOD-2) and heme oxygenase-1 (HO-1) after exposure to S-MWCNT, the level of TNF- $\alpha$ release by these macrophage cells in vitro was significantly decreased. These findings suggest that the pro-inflammatory response caused by MWCNTs is often oxidant mediated, in contrast to the results shown in the present study. A possible reason for such effects seen could be attributed to the surfactant used to originally disperse the MWCNT sample. Although all CNTs had the same final dispersant (i.e., 'biological buffer'), the MWCNTs and SWCNTs were dispersed using chemical surfactants [33, 34, 45]. Specifically the MWCNTs were dispersed in 160 ppm of Pluronic F127 in MilliQ $\mathrm{H}_{2} \mathrm{O}$ [34]. This has been shown not to cause any ROS or TNF- $\alpha$ production amongst numerous other tests (e.g., GSH depletion and IL-8 production in epithelial cells [37]) on its own, and could, in theory, be attributed to masking any ROS formed by the MWCNTs due to its abundance upon the surface of the MWCNTs. The TNF- $\alpha$ increase could therefore not be a simple result of the MWCNTs themselves, but due to the specific interaction (active entry mechanism) of the MWCNTs with the MDM, in which MWCNTs gain entry into the MDM and localise within membranebound compartments, as previously shown by Clift et al. [36]. Both the NTT and NTS samples however, were also internalized via a proposed active mechanism (i.e., found to be present within vesicles inside macrophage cells $[24,27])$ although showed no pro-inflammatory effects. The NTT and NTS samples were originally dispersed in a $0.5 \%$ bovine serum albumin (BSA) solution. It is possible that, the BSA 'coating' has a further protective effect for both the NTT and NTS samples compared to the Pluronic 'coated' MWCNTs, which may, within highly acidic environments degrade from the CNT surface and allow for direct interaction of the MWCNTs with the immune cell machinery. Further research would have to be performed to confirm this hypothesis however, and determine the long-term, in situ stability of differently dispersed CNTs in vitro and how this may contribute to an adverse biological impact of CNTs. 
In summary therefore, the present study has shown that for different biological endpoints, different physical aspects of industrial CNTs can be associated with the onset of a severe, negative biological effect in vitro. Whilst some of the effects noted can be clearly associated with the physico-chemical characteristics of the CNTs (i.e., ROS production of NTL MWCNTs), other reactions (e.g., TNF- $\alpha$ production by MWCNTs in MDM) are more complicated. In the latter, not only does the material play a role in the biological impact, but the manner in which it interacts with the biological system is important. In conclusion therefore, from the data presented within the present manuscript, it is possible to state that the specific morphology of the CNTs can contribute to the adverse biological responses observed, yet are not entirely responsible for the observed biological impact of CNTs upon immune cells in vitro.

\section{Materials and methods}

\section{Chemical and reagents}

All chemicals and reagents used were purchased from Sigma-Aldrich (Switzerland), unless otherwise stated.

\section{CNT physico-chemical characteristics}

A series of five different physico-chemical CNTs, that are industrially available and produced via chemical vapor deposition (CVD), were used in this study; single-walled bundled CNTs (SWCNTs), multi-walled bundled CNTs (MWCNTs), tangled MWCNTs (NTT), long MWCNTs (NTL), and short MWCNTs (NTS). The characteristics of the different CNTs used have previously been reported in the literature by Wick et al. [33] (SWCNT), Thurnherr et al. [34] (MWCNT), Poland et al. [24] (NTT, NTL) and Murphy et al. [26] (NTS) and are detailed in Table 1. The key physico-chemical characteristics of each CNT are described in Table 1. The length, diameter, and morphology of each CNT were obtained in all four studies by transmission electron microscopy (TEM) and scanning electron microscopy (SEM). Determination of metal contamination was achieved via inductive coupled plasma mass spectrometry (ICP-MS) for the SWCNTs, NTT and NTL, respectively [24, 33]. Thurnherr et al. [34] assessed the metal contaminations of the MWCNTs by inductive coupled plasma optical emission spectrometry (ICP-OES). Information related to the metal contaminants contained within the NTS sample was provided by the suppliers (Table 1). No endotoxin content, assessed by the limulous amoebocyte lysate (LAL) test, is known to be present within any of the CNT samples [10, 24, 26].

\section{Preparation of CNT samples}

In order to have a well-dispersed stock solution, SWCNTs were dispersed in the surfactant Tween 80 at a concentration of $0.04 \mathrm{mg} / \mathrm{mL}$, whereas the MWCNTs were dispersed in Pluronic F127 at a concentration of 160 ppm [33]. Dry powder samples of the NTT, NTL, and NTS were prepared at a concentration of $1 \mathrm{mg} / \mathrm{mL}$ using the method previously reported by Poland et al. [24]. Each dry powder sample was suspended in Rosewell Park Memorial Institute (RPMI 1640) medium supplemented with $0.5 \%$ bovine serum albumin (BSA), $1 \%$ L-glutamine (L-G) (100 U/ $\mathrm{mL}$ ) and $1 \%$ penicillin/streptomycin $(\mathrm{P} / \mathrm{S})(0.1 \mu \mathrm{g} / \mathrm{mL})$ (hereby referred to as 'BSA Media'), sonicated for $4 \mathrm{~h}$ (Bransonic, Branson, Switzerland) and then sterile filtered to obtain a well dispersed solution.

All five CNTs were then suspended in RPMI 1640 complimented with 10\% fetal calf serum (FCS), 1\% L-G and 1\% P/S (hereby referred to as 'biological buffer') at nanofibre concentrations of $0.005,0.01$, and $0.02 \mathrm{mg} / \mathrm{mL}$. To control for the effects of suspending the CNTs in FCS, samples at concentrations of 0.005$0.02 \mathrm{mg} / \mathrm{mL}$ were also prepared in RPMI 1640 supplemented with only $1 \%$ L-G and $1 \%$ P/S, and no FCS content. Samples were subsequently sonicated (Bransonic, Branson, Switzerland) for $10 \mathrm{~min}$ prior to being investigated in terms of their ability to cause cytotoxicity, pro-inflammatory cytokine stimulation and reactive oxygen species production following exposure to human blood monocyte derived macrophages (MDM).

\section{Cell culture}

MDM were isolated from human buffy coat (Blutspendezentrum, Bern, Switzerland) using a density gradient centrifugation as previously described by Lehmann et al. [46]. In order to confirm a pure MDM population, the blood isolated leukocytes were stained with magnetic beads specific for the MDM surface protein CD14 and passed through a magnetic filter [47]. CD14 $\mathrm{MDM}$ were subsequently cultured for 6 days at $37^{\circ} \mathrm{C}, 5 \% \mathrm{CO}_{2}$ in the presence of $10 \mathrm{ng} / \mathrm{mL}$ of macrophage colony-stimulating factor (M-CSF) in the biological buffer.

\section{CNT cell exposure}

After the 6-day culture period, MDM were seeded into a 12-well plate (TPP, $\mathrm{CH}$ ) at a density of $1 \times 10^{6}$ cells $/ \mathrm{mL}$ ( $1 \mathrm{~mL}$ volume per well) and cultured at $37^{\circ} \mathrm{C}, 5 \% \mathrm{CO}_{2}$ for $24 \mathrm{~h}$. Following the incubation period, MDM were exposed (via suspension exposure) to each different CNT sample at a nanofiber concentration of $0.005,0.01$, or $0.02 \mathrm{mg} / \mathrm{mL}$ for $24 \mathrm{~h}$ at $37^{\circ} \mathrm{C}, 5 \% \mathrm{CO}_{2}$. After the exposure period, the cellular supernatant was collected and either stored at $4^{\circ} \mathrm{C}$ or $-80^{\circ} \mathrm{C}$ for subsequent biochemical analysis. MDM were then prepared for an assessment of their cellular morphology via light microscopy, as described below.

\section{Cellular morphology}

MDM were washed once with $1 \times$ phosphate buffered saline (PBS) and then fixed using 3\% paraformaldehyde (PFA) in PBS (Merck, Switzerland) for $15 \mathrm{~min}$ at room temperature. After fixation, the PFA-PBS solution was removed and MDM were washed once with $1 \times$ PBS. MDM were then imaged using a conventional light microscope (AE200, Motic, Switzerland) containing a digital camera (Nikon, Switzerland) at a magnification of $40 \times$ (N.A. 0.5). 


\section{Biochemical analysis}

\section{Cytotoxicity}

\section{Assessment of lactate dehydrogenase release}

The cytosolic enzyme lactate dehydrogenase (LDH) was measured to provide an indication of the cell membrane permeability and associated potential cytotoxicity of the different CNT samples to the MDM. LDH was measured in MDM supernatants using a diagnostic detection kit (Roche, Switzerland). As a positive control, Triton $\times 100$ at a concentration of $0.2 \%$ in PBS (Fluka, Switzerland) was used.

\section{Assessment of LDH adsorption}

To determine if each CNT sample was interfering with the LDH enzyme and thus eliciting a false-negative or positive result [48] an assessment of the ability for CNT to adsorb or to concentrate the LDH enzyme was performed using the method previously described by Clift et al. [35].

\section{Reactive oxygen species production}

Reactive oxygen species (ROS) are a natural by-product of oxygen production and are important for intracellular signaling pathways. Since CNTs have been shown to cause ROS production independent of their interaction with mammalian cells (i.e., in a cell-free environment) [39], the CNTs used in the present study were assessed for their ROS production in both a cell-free environment and also following exposure to MDM. On both occasions, an adapted version of the protocol previously described by Wilson et al. [49] and Foucard et al. [50], the fluorescent probe $2^{\prime}, 7^{\prime}$-dichlorfluorecein-diacetate $\left(\mathrm{DCFH}_{2}\right.$ DA) which is degraded by ROS, cleaving the molecule to DCF which subsequently elicits a fluorescent signal [51], was used. Furthermore, the compound horse-radish peroxidase was used to amplify any ROS signal present [43].

\section{ROS production in a cell-free environment}

Briefly, in a 96-well plate (white, solid bottom plate [Berthold Technologies, Germany]) $200 \mu \mathrm{L}$ of HBSS-HRP solution (Hanks Buffered Salt Solution (Gibco, Switzerland) containing Horse-radish peroxidase (3 mg/mL) (Fluka, Switzerland) at a 1:32 ratio] was mixed with 1 $\mu \mathrm{L} \mathrm{DCFH}_{2}$-DA solution (DCFH+) [ $\mathrm{DCFH}_{2}$-DA (Invitrogen, Switzerland) diluted 1:4 with methanol to $1 \mathrm{mM}$ ]. Subsequently, this solution was further diluted 1:10 with either sodium hydroxide $(0.01 \mathrm{mM})(\mathrm{NaOH}$, $2.5 \mathrm{mg}$ in $1 \mathrm{~L}$ of MilliQ water) or $1 \mu \mathrm{L}$ DCFH- solution [methanol, $\mathrm{NaOH}$ $(0.01 \mathrm{mM})$ and $1 \times$ PBS mixed at a ratio of 1:4:15], respectively. The fluorescent intensity of each well in the 96 well-plate was then measured using a fluorimeter (TriStar LB 941, Berthold Technologies, Germany) at a wavelength of $488 \mathrm{~nm}$. After this baseline measurement, a total of $45 \mu \mathrm{L}$ of either the CNT samples (prepared in biological buffer) or the positive control [tert-butyl hydrogen peroxide (70\% solution) ( $t \mathrm{BHP}, \mathrm{CH})$ mixed with $1 \times \mathrm{PBS}(1: 12,000)]$ was then added to the corresponding wells in the 96-well plate. Each well was then measured in 1-min intervals over a 10-min period using the fluorimeter (TriStar LB 941, Berthold Technologies, Germany) at a wavelength of $488 \mathrm{~nm}$. Following acquisition, data was subsequently calculated and expressed as a percentage of the negative control (biological buffer) value.

\section{ROS production in MDM}

ROS formation within MDM exposed to each different CNT sample was performed using fluorescence activated cell sorting (FACS) (LSR Fortessa, BD Biosciences, Switzerland). MDM a density of $1 \times 10^{5}$ cells/ $\mathrm{mL}$ were seeded in $5 \mathrm{~mL}$ FACS tubes (BD Biosciences, Switzerland) and cultured for $24 \mathrm{~h}$ at $37^{\circ} \mathrm{C}, 5 \% \mathrm{CO}_{2}$. MDM were then washed; samples were centrifuged for $8 \mathrm{~min}$ at $1300 \mathrm{rpm}$ to form a cell pellet. The remaining supernatant was discarded and MDM were re-suspended with biological buffer containing $\mathrm{CD}_{1} 4^{+}$at a 1:50 dilution (BD Biosciences, Switzerland). Samples were then incubated for $1 \mathrm{~h}$ at $37^{\circ} \mathrm{C}$, $5 \% \mathrm{CO}_{2}$. MDM were then washed twice: centrifugation for $8 \mathrm{~min}$ at $1300 \mathrm{rpm}$, removal of supernatant and re-suspension of cells in fresh biological buffer. The supernatant was discarded and MDM were exposed to the DCFH+ solution (DCFH diluted 1:4 in methanol and then 1:10 in $1 \times \mathrm{PBS}$ ) for $30 \mathrm{~min}$ at $37^{\circ} \mathrm{C}, 5 \% \mathrm{CO}_{2}$. After the incubation period samples were washed once, and then re-suspended with $500 \mu \mathrm{L}$ of FACS buffer (1× PBS containing 1\% BSA and $0.1 \%$ sodium azide). Using consistent parameters the geometric mean fluorescent intensity (GMFI) was analysed immediately at each time point using two-colour flow cytometry (LSR Fortessa, BD Biosciences, Switzerland). Fluorescent signals were collected in logarithmic mode (4 decade logarithmic amplifier) and cell numbers per channel in linear mode. To identify the MDM population, an electronic gate was placed around the forward and side scatter modes with 10,000 gated events acquired for analysis. The fluorescent amplifiers of the detector filters were adjusted to ensure that the negative cell population appeared in the first logarithmic decade. An electronic marker was then placed at the limit of the negative control to express all positive cell populations in the final three logarithmic decades. Compensation for spectral overlap was performed automatically using the BD FACSDiva computational software. Following acquisition, data was subsequently calculated and expressed as a percentage of the negative control (biological buffer) value.

\section{Pro-inflammatory response}

\section{Tumor necrosis factor-alpha release}

Tumor necrosis factor (TNF)- $\alpha$ is the primary cytokine released by macrophages in response to inflammatory stimuli. TNF- $\alpha$ regulates the activation of other immune cells, apoptosis, cell proliferation, and the release of other cytokines. The concentration of the released pro-inflammatory cytokine TNF- $\alpha$ (in MDM supernatant) was determined using an enzyme-linked immunosorbant assay (ELISA) (R\&D Systems, Switzerland). Lipopolysaccharide (LPS) $(0.1 \mathrm{mg} / \mathrm{mL})$ was used as a positive control.

\section{TNF- $\alpha$ adsorption}

Adsorption of the CNTs to the TNF- $\alpha$ protein, or vice-versa, was performed to exclude any false-positive or false-negative results. Briefly, each different CNT sample, at a nanofiber concentration of 0.005 , 0.01 , or $0.02 \mathrm{mg} / \mathrm{mL}$, was incubated with TNF- $\alpha(10 \mathrm{ng} / \mathrm{mL})$ at volume of $500 \mu \mathrm{L}$ in an environment of $37^{\circ} \mathrm{C}, 5 \% \mathrm{CO}_{2}$ for $1 \mathrm{~h}$. After the incubation period, all samples were then assessed for their TNF- $\alpha$ content by ELISA (R\&D Systems, Switzerland). 


\section{Data and statistical analysis}

The data is presented as mean \pm standard error of the mean (SEM). All data was found to be normally distributed (data not shown). To determine statistical significance between the qualitative data sets, a oneway ANOVA was used with a Tukey's post-hoc test (SPSS, IBM, USA). Results were considered significant if $\mathrm{p}<0.05$. A confidence interval of $95 \%$ was accepted.

Acknowledgments: The authors would like to acknowledge the Adolphe Merkle Foundation, an Empa internal grant, as well as the Swiss National Science Foundation, the Swiss National research Programme 64 and the Swiss Nanoscience Institute (SNI) within the National Center of Research (NCCR) in Nanoscale Science for their financial support. The authors also thank Vicki Stone (Heriot-Watt University, Edinburgh, UK), Craig A. Poland (Institute of Occupational Medicine, Edinburgh, UK) Ken Donaldson and Rodger Duffin (Edinburgh University, UK) for their kind donation of the NTT, NTL and NTS samples.

Conflict of interest statement: The authors declare no conflict of interest. The authors are entirely responsible for the data contained within and the writing of the manuscript.

Received July 29, 2013; accepted October 9, 2013; previously published online November 6, 2013

\section{References}

1. Piccinno F, Gottschalk F, Seeger S, Nowack B. Industrial production quantities and uses of ten engineered nanomaterials in Europe and the world. J Nanopart Res 2012;14:1109.

2. Kostarelos K, Bianco A, Prato M. Promises, facts and challenges for carbon nanotubes in imaging and therapeutics. Nat Nanotech 2009;4:627-33.

3. Robertson J. Realistic applications of CNTs. Mater Today 2004;7:46-52.

4. NIOSH. General safe practices for working with engineered nanomaterials in research laboratories. Cincinnati, OH: U.S. Department of Health and Human Services, Centers for Disease Control, National Institute for Occupational Safety and Health, DHHS (NIOSH) Publication No. 2012-147, 2012.

5. Maynard AD, Baron PA, Foley M, Shvedova AA, Kisin ER, Castranova V. Exposure to carbon nanotube material: aerosol release during the handling of unrefined singlewalled carbon nanotube material. J Tox Environ Health Part A 2004;67:87-107.

6. Mueller L, Gasser M, Raemy DO, Herzog F, Brandenberger C, Schmid O, et al. Realistic exposure methods for investigating the interaction of nanoparticles with the lung at the air-liquid interface in vitro. InSci J (Nanotech) 2011;1:30-64.

7. Oberdorster G, Stone V, Donaldson K. Toxicology of nanoparticles: a historical perspective. Nanotox 2007;1:2-25.

8. Rothen-Rutishauser B, Blank F, Muehlfeld C, Gehr P. In vitro models of the human epithelial airway barrier to study the toxic. potential of particulate matter. Exp Opin Drug Metab Toxicol 2008;4:1075-89.

9. Van Berlo D, Clift MJ, Albrecht C, Schins RP. Carbon nanotubes: an insight into the mechanisms of their potential genotoxicity. Swiss Med Wkly 2012;142:w13698.

10. Clift MJ, Foster EJ, Vanhecke D, Studer D, Wick P, Gehr P, et al. Investigating the interaction of cellulose nanofibers derived from cotton with a sophisticated 3D human lung cell coculture. Biomacromol 2011;12:3666-73.

11. Timbrell J. Principles of biochemical toxicology. CRC Press, UK: Taylor and Francis, 1999.

12. Wick P, Clift MJ, Rosslein M, Rothen-Rutishauser B. A brief summary of the past 20 years of carbon nanotubes in science: a health and safety perspective. Chemsuschem 2011;4: 905-11.

13. Johnston HJ, Hutchison GR, Christensen FM, Peters S, Hankin S, Aschberger K, et al. A critical review of the biological mechanisms underlying the in vivo and in vitro toxicity of carbon nanotubes: the contribution of physico-chemical characteristics. Nanotox 2010;4:207-46.

14. NIOSH Current Intelligence Bulletin 65. Occupational exposure to carbon nanotubes and nanofibres. Cincinnati, $\mathrm{OH}$ : U.S. Department of Health and Human Services, Centers for Disease Control, National Institute for Occupational Safety and Health, DHHS (NIOSH) Publication No. 2013-145, 2013.

15. Lam CW, James JT, McCluskey R, Hunter RL. Pulmonary toxicity of single-wall carbon nanotubes in mice 7 and 90 days after intratracheal instillation. Toxicol Sci 2004;77:126-34.

16. Shvedova AA, Kisin ER, Mercer R, Murray AR, Johnson VJ, Potapovich Al, et al. Unusual inflammatory and fibrogenic pulmonary responses to single-walled carbon nanotubes in mice. Am J Physiol Lung Cell Mol Physiol 2005;289: L698-708.

17. Muller J, Huaux F, Moreau N, Misson P, Heilier JF, Delos M, et al. Respiratory toxicity of multiwall carbon nanotubes. Toxicol Appl Pharmacol 2005;207:221-31.

18. Shvedova AA, Kisin E, Murray AR, Johnson VJ, Gorelik O, Arepalli S, et al. Inhalation vs. aspiration of single-walled carbon nanotubes in C57BL/6 mice: inflammation, fibrosis, oxidative stress, and mutagenesis. Am J Physiol Lung Cell Mol Physiol 2008;295:L552-65.

19. Ma-Hock L, Treumann S, Strauss V, Brill S, Luizi F, Mertler M, et al. Inhalation toxicity of multi-wall carbon nanotubes in rats exposed for 3 months. Toxicol Sci 2009;112:468-81.

20. Pauluhn J. Subchronic 13-week inhalation exposure of rats to multiwalled carbon nanotubes: toxic effects are determined by density of agglomerate structures, not fibrillar structures. Toxicol Sci 2010;113:226-42.

21. Porter DW, Hubbs AF, Mercer RR, Wu N, Wolfarth MG, Sriram K, et al. Mouse pulmonary dose- and time course-responses induced by exposure to multi-walled carbon nanotubes. Toxicol 2010;269:136-47. 
22. Mercer RR, Hubbs AF, Scabilloni JF, Wang L, Battelli LA, Friend S, et al. Pulmonary fibrotic response to aspiration of multiwalled carbon nanotubes. Part Fibre Toxicol 2011;8:21.

23. Stanton MF, Layard M, Tegeris A, Miller E, May M, Kent E. Carcinogenicity of fibrous glass: pleural response in the rat in relation to fiber dimension. J Nat Can Inst 1977;58:587-603.

24. Poland CA, Duffin R, Kinloch I, Maynard A, Wallace WA, Seaton $A$, et al. Carbon nanotubes introduced into the abdominal cavity ofmice show asbestoslike pathogenicity in a pilot study. Nat Nanotech 2008;3:423-8.

25. Donaldson K, Murphy FA, Duffin R, Poland CA. Asbestos, carbon nanotubes and the pleural mesothelium: a review of the hypothesis regarding the role of long fibre tetention in the parietal pleura, inflammation and mesothelioma. Part Fibre Toxicol 2010;7:5.

26. Murphy FA, Poland CA, Duffin R, Al-Jamal KT, Ali-Boucetta H, Nunes $A$, et al. Length-dependent retention of carbon nanotubes in the pleural space of mice initiates sustained inflammation and progressive fibrosis on the parietal pleura. Am J Path 2011;178:6.

27. Murphy FA, Schinwald A, Poland CA, Donaldson K. The mechanism of pleural inflammation by long carbon nanotubes: interaction of long fibers with macrophages stimulates them to amplify proinflammatory responses in mesothelial cells. Part Fibre Toxicol 2012;9:8.

28. Fenoglio I, Greco G, Tomatis M, Muller J, Raymundo-Pinìfero E, Beguin Fo, et al. Structural defects play a major role in the acute lung toxicity of multiwall carbon nanotubes: physicochemical aspects. Chem Res Tox 2008;21:1690-7.

29. Muller J, Huaux Fo, Fonseca A, Nagy JB, Moreau N, Delos M, et al. Structural defects play a major role in the acute lung toxicity of multiwall carbon nanotubes: toxicological aspects. Chem Res Tox 2008;21:1698-705.

30. Tian F, Cui D, Schwarz H, Estrada GG, Kobayashi H. Cytotoxicity of single-wall carbon nanotubes on human fibroblasts. Toxicol In Vitro 2006;20:1202-12.

31. Stone V, Johnston H, Schins RP. Development of in vitro systems for nanotoxicology: methodological considerations. Crit Rev Toxicol 2009;39:613-26.

32. Donaldson K, Aitken R, Tran L, Stone V, Duffin R, Forrest G, et al. Carbon nanotubes: a review of their properties in relation to pulmonary toxicology and workplace safety. Toxicol Sci 2006;92:5-22.

33. Wick P, Manser P, Limbach LK, Dettlaff-Weglikowska U, Krumeich F, Roth S, et al. The degree and kind of agglomeration affect carbon nanotube cytotoxicity. Tox Letts 2007;168:121-31.

34. Thurnherr T, Su DS, Diener L, Weinberg G, Manser P, Pfaender N, et al. Comprehensive evaluation of in vitro toxicity of three large-scale produced carbon nanotubes on human Jurkat T cells and a comparison to crocidolite asbestos. Nanotox 2009;3: 319-38.

35. Clift MJ, Rothen-Rutishauser B, Brown DM, Duffin R, Donaldson K, Proudfoot $L$, et al. The impact of different nanoparticle surface chemistry and size on uptake and toxicity in a murine macrophage cell line. Toxicol Appl Pharm 2008;232:418-27.
36. Clift MJ, Gehr P, Rothen-Rutishauser B. In vitro testing for nanotoxicology: a valid alternative? Arch Toxicol 2011;85:723-31.

37. Clift MJ, Endes C, Vanhecke D, Wick P, Gehr P, Schins RP, et al. A comparative study of different in vitro lung cell culture systems to assess the most beneficial tool for screening the potential adverse effects of carbon nanotubes. Toxicol Sci (in Press).

38. Donaldson K, Stone V, Borm PJ, Jimenez LA, Gilmour PS, Schins RP, et al. Oxidative stress and calcium signaling in the adverse effects of environmental particles (PM10). Free Rad Biol Med 2003;34:1369-82.

39. Brown DM, Kinloch IA, Bangert U, Windle AH, Walter DM, Walker GS, et al. An in vitro study of the potential of carbon nanotubes and nanofibres to induce inflammatory mediators and frustrated phagocytosis. Carbon 2007;45:1743-56.

40. Donaldson K, Tran CL. Inflammation caused by particles and. fibers. Inhal Toxicol 2002;14:5-27.

41. Locksley RM, Killeen N, Lenardo MJ. The TNF and TNF receptor superfamilies: integrating mammalian biology. Cell 2001;104:487-501.

42. Kagan VE, Konduru NV, Feng W, Allen BL, Conroy J, Volkov Y, et al. Carbon nanotubes degraded by neutrophil myeloperoxidase induce less pulmonary inflammation. Nat. Nanotech 2010;5:354-9.

43. Rothen-Rutishauser B, Brown DM, Piallier-Boyles M, Kinloch IA, Windle AH, Gehr P, et al. Relating the physicochemical characteristics and dispersion of multiwalled carbon nanotubes in different suspension media to their oxidative reacitivity in vitro and inflammation in vivo. Nanotox 2010;4:331-42.

44. Bussy C, Pinault M, Cambedouzou J, Landry MJ, Jegou P, Mayne-L'hermite $M$, et al. Critical role of surface chemical modifications induced by length shortening on multi-walled carbon nanotubes-induced toxicity. Part Fibre Toxicol 2012;9:46.

45. Thurnherr T, Brandenberger C, Fischer K, Diener L, Manser P, Maeder-Althaus X, et al. A comparison of acute and long-term effects of industrial multiwalled carbon nanotubes on human lung and immune cells in vitro. Tox Letts 2011;200:176-86.

46. Lehmann A, Brandenberger C, Blank F, Gehr P, RothenRutishauser B. A 3D model of the human epithelial airway barrier. In: Yarmush ML, Langer RS, editors. Alternatives to animal testing. Artech House 2010:239-60.

47. Steiner S, Muller L, Popovicheva OB, Raemy DO, Czerwinski J, Comte $\mathrm{P}$, et al. Cerium dioxide nanoparticles can interfere with the associated cellular mechanistic response to diesel exhaust exposure. Tox Letts 2012;214:218-25.

48. Worle-Knirsch JM, Pulskamp K, Krug HF. Oops they did it again! Carbon nanotubes hoax scientists in viability assays. Nano Letts 2006;6:6.

49. Wilson MR, Lightbody JH, Donaldson K, Sales J, Stone V. Interactions between ultrafine particles and transition metals in vivo and in vitro. Toxciol Appl Pharm 2002;184:172-9.

50. Foucaud L, Wilson MR, Brown DM, Stone V. Measurement of reactive species production by nanoparticles prepared in biologically relevant media. Tox Letts 2007;174:1-9.

51. Pal AK, Bello D, Budhlall B, Rogers E, Milton DK. Screening for oxidative stress elicited by engineered nanomaterials: evaluation of acellular DCFH Assay. Dose-Response 2012;10:308-30. 